\title{
ECOLOGICAL FEATURES AND SPECIES DIVERSITY OF EPIPHYTIC MYXOMYCETES (MYXOMYCETES) ON AN ORDINARY PINE (PINUS SYLVESTRIS L.) IN THE FOREST-STEPPE AND STEPPE ZONES OF THE SOUTHEAST OF WESTERN SIBERIA
}

(C) 2017

Vlasenko Anastasiya Vladimirovna, candidate of biological sciences, researcher of Lower Plants Laboratory Vlasenko Vyacheslav Alexandrovich, candidate of biological sciences, senior researcher of Lower Plants Laboratory

Central Siberian Botanical Garden of Siberian Branch of Russian Academy of Sciences

(Novosibirsk, Russian Federation)

\begin{abstract}
The species diversity and taxonomic structure of myxomycetes of the epiphytic-corticoid complex has been studied in pine forests on the Pinus sylvestris. The study area is located in the Asian part of Russia, in the southeast of the West Siberian Plain. Species diversity has been revealed using the classical method of «moistchambers», based on the presence in the life cycle of mucus staggering stages - microcysts and sclerotia, from which, under certain favorable conditions, plasmodium and, later, fruit bodies - sporocarpas may appear in the Petri dish. We selected 720 packages for the installation of «moist-chambers» between 2008 and 2016 in the study area. The experiments with «moist-chambers» were performed between 2008 and 2017. We received 361 samples of the myxomycetes. A sample is a colony of sporocarpas derived from a single plasmodium. As a result of taxonomic identification we received 28 species of Myxomycetes belonging to 5 orders, 7 families, and 13 genera on the pine bark. It is noted that 6 species of Myxomycetes develop on the pine bark, absent in the area of the study on the bark of other tree species - Echinostelium fragile, Paradiacheopsis rigida, Physarum auriscalpium, Ph. mutabile, Stemonaria nannengae, Willkommlangea reticulata.

Keywords: Myxomycetes; species diversity; fungus-like protists; biodiversity; slime molds; Asian Russia; Western Siberia; stripe pine forests; forest-steppe; steppe; Altai Region; Novosibirsk Region; taxonomic structure; Pinus sylvestris; substrate complexes; subformations; epiphytes.
\end{abstract}

\section{АНАЛИЗ ЭКОЛОГИЧЕСКОГО ПРОСТРАНСТВА ЭДИФИКАТОРОВ И АССЕКТАТОРОВ ЮЖНО- ТАЁЖНЫХ ЛЕСОВ ЧЕЛЯБИНСКОЙ ОБЛАСТИ С ИСПОЛЬЗОВАНИЕМ ШКАЛ Д.Н. ЦЫГАНОВА} (C) 2017

Гетманец Ирина Анатольевна, доктор биологических наук, заведующий кафедрой общей экологии Москвина Ирина Валерьевна, аспирант кафедры общей экологии Челябинский государственный университет (2. Челябинск, Российская Федерачия) Артёменко Борис Александрович, кандидат биологических наук, исполняющий обязанности заведующего кафедрой теории, методики и менеджмента дошкольного образования Южно-Уральский государственный гуманитарно-педагогический университет (2. Челябинск, Российская Федерачия)

Аннотация. На основе экологических шкал Д.Н. Цыганова по геоботаническим описаниям, с использованием компьютерной программы «EcoScaleWin» проведена фитоиндикация экотопов еловых лесов на западном склоне горы Липовой в пределах территории Кусинского района. Ценотические свойства видов оценены по их обилию в типовых сообществах, определены лимитирующие факторы, экологическая валентность и толерантность, оценена степень использования экологических потенций и эффективность освоения экологического пространства, описаны совокупные параметры местообитаний. Оценена вертикальная структура и состав древостоя ельников, показано, что Picea obovata отмечена во всех ярусах, где также присутствуют Betula pendula и Pinus sylvestris, но их численность варьируется в пределах 10-20\% от общего числа всех особей исследуемого участка. Отмечается неравномерность распределения древостоя, выраженность «окон возобновления», к которым тяготеет подрост березы повислой. Проанализировано соотношение видов эколого-ценотических групп и показано, что в сообществах преобладают виды бореальной и боровой групп, достаточно большой вклад вносят неморальная и луговая (включая высокотравную) группы, небольшой процент приходится на виды нелесной группы (водно-болотные и плюризональные). Биоморфологический анализ выявил, что жизненная форма стабильна, представлена одноствольным деревом с различной формой кроны, что свидетельствует о разном возрасте особей ели сибирской. Исследуемый фитоценоз отнесен к позднесукцессионным сообществам, позднему этапу восстановительной сукцессии, так как доминантом является типично конкурентный вид. Материалы исследования могут служить основой для мониторинга растительных сообществ и ценопопуляций, определения потенциального видового богатства фитоценозов.

Ключевые слова: толерантность; экологическая валентность; экологические шкалы; фитоиндикация; эдификаторы; ассектаторы; эколого-ценотические группы; экотоп; ценопопуляция; фитоценоз; древостой; Челябинская область; Кусинский район; геоботанические описания; гора Липовая.

\section{Введение}

Особая значимость лесных сообществ как объектов для познания функциональной организации растительного покрова состоит в том, что биологиче- ские особенности эдификаторов определяют структуру и динамику фитоценозов в целом. В настоящее время для оценки фитоценозов все большее значение приобретают фитоиндикационные подходы, базиру- 
ющиеся на оценке экологических параметров местообитаний по произрастающим на нём видам растений, где в качестве фитометров выступают растительные сообщества, группировки видов и другие ценотические единицы. Этот подход - достаточно распространённая и традиционная процедура в современных геоботанических и экологических исследованиях. Экологические шкалы (Л.Г. Раменский [1], H. Ellenberg [2], E. Landolt [3], Д.Н. Цыганов [4]) и серия региональных шкал (В.П. Королюк [5], Т.А. Комарова и др. [6]) успешно использованы для анализа экологического разнообразия видов разных биоморф, произрастающих в природных экосистемах республик Марий-Эл, Татарстана, Чувашии и ряда областей: Архангельской, Московской, Иркутской и др. (Ю.А. Дорогова, Л.А. Жукова [7], Л.А. Жукова, Ю.А. Дорогова, Н.В. Турмухаметова [8], Т.А. Полянская [9]).

Климатопические и эдафотопические факторы, создающие соответствующие режимы в условиях геотопов растений, можно определять непосредственным измерением показателей среды. (П.Я. Дидух, П.Я. Плюта, Г.Н. Каркуциев [10], Л.Б. Заугольнова и др. [11]). Но часто оказывается, что вследствие исследования протяжённых территориальных выделов использование приборной базы и инструментальных методов не всегда представляется возможным. Учитывая имеющийся положительный опыт многих поколений исследователей, можно определить совокупные экологические параметры местообитаний на основе поведения самих видов (их присутствия и обилия), выступающих в роли своеобразных фитометров, интегрируя своей реакцией влияние прямодействующих факторов среды, т.е. непосредственных свойств местообитания особей.

Метод стандартных экологических шкал относится к категории маршрутных полевых методов, основанных на изучении экологических рядов, под которыми в экологии растений понимают последовательные изменения обилия и состава ценопопуляций вдоль градиентов среды.

С этих позиций можно охарактеризовать экологические свойства каждого вида фитоценоза. Такой метод выявления экологических диапазонов или оптимумов представляют соответственно шкалы Л.Г. Раменского, Д.Н. Цыганова, а также Г. Элленберга и Э. Ландольта и др.

Использование компьютерных программ на основе экологических шкал позволяет обрабатывать геоботанические описания и получать точечные и диапазонные оценки для ценопопуляций каждого вида растений по интересующему исследуемому фактору и совокупную оценку местообитаний [12, с. 87-89]. Такие полуколичественные методы практически значимы благодаря своей точности, а растительные группировки, выступающие в качестве фитометров, способны объективнее, чем инструментальные методы, оценить изменения экологической обстановки.

Стандартные экологические шкалы, вопросы их применения, а также верификация инструментально измеренных параметров местообитания на соответствие характеристикам, рассчитанным по шкалам, исследуются в целом ряде работ (П.С. Широких [13], Е.А. Зубкова [14], Т.А. Полянская [9], Е.С. Золотова, Н.С. Иванова [15], И.А. Гетманец, Ю.А. Серебренникова [16]).
По мнению А.А. Ниценко [17], ценотическая роль одного и того же вида в разных частях ареала изменяется, поэтому выявление эколого-ценотических групп в растительном покрове различных регионов остаётся и сегодня актуальной задачей. Кроме того, анализ ЭЦГ представляет действенный инструмент, который наравне с анализом присутствия ключевых видов используется в исследованиях дискретности сообществ, выраженности функциональных смен видового состава, что является одной из актуальных проблем фитоценологии [18, с. 174-181].

Данная работа представляет дальнейшую разработку фитоиндикационного направления, цель которой - выявить экологические характеристики и экологическое пространство эдификаторов и ассектаторов южно-таёжных лесов.

\section{Материалы и методы исследования}

Исследования проведены в 2012-2017 годах, объектом выбран участок площадью 0,5 га елового леса, расположенного на самом протяжённом хребте западного террасовидного склона горы Липовой в подзоне южно-таёжных лесов Челябинской области в пределах территории Кусинского района.

Согласно материалам Л.А. Соколовой [19], наибольшая роль в сложении растительного покрова этой подзоны принадлежит сосновым, лиственнично-сосновым и смешанным сосново-березовым лесам, господствующим в окрестностях крупных промышленных населённых пунктов и в межгорных депрессиях, приуроченных к широким и продольным участкам долин рек Юрюзани, Катава, Сатки, Ая, Кусы, Уфалея, Нязи и Уфы. Склоны горных хребтов Уфимского амфитеатра, обращенные на запад, открыты прямому действию влажных атлантических воздушных масс, покрыты пихтово-елово-кисличниковыми лесами и широколиственно-елово-папоротниковыми лесами с высоким разнотравьем. Согласно лесоустроительным данным, леса имеют III-IV класс бонитета с хорошо развитым подлеском [20].

Для выявления количественной оценки использования каждого фактора эдификаторами рассчитана потенциальная экологическая валентность (PEV) как мера приспособленности ценопопуляции (ЦП) конкретного вида к изменению одного экологического фактора. Величина PEV равна доли диапазона ступеней конкретного вида от всей шкалы:

$$
P E V=\frac{\sum_{\text {ступений позиции вида }}}{\sum_{\text {ступеней шкалы }}}
$$

Объекты исследования были проанализированы по 9 шкалам Д.Н. Цыганова (температурного режима - Tm, континентальности - Kn, омброклиматической - Om, криоскопической - $\mathrm{Cr}$, освещения/затенения Lc, увлажнения почв - Hd, трофности - Tr, нитрификации - Nt, кислотности - Rc).

Для характеристики отношения конкретного вида к совокупному воздействию нескольких факторов вычислен индекс толерантности (It) в долях или мера стено- и эврибионтности по формуле:

$$
I t=\frac{\sum_{P E V}}{\text { число шкал рассматриваемых факторов }}
$$

В ходе маршрутной рекогносцировки выявлены однородные участки растительности, площадь которых определена размером фитогенного поля деревьев и составила $25 \times 25$ м, на которых проведены стан- 
Гетманец И.А., Москвина И.В., Артёменко Б.А.

дартные геоботанические описания с регистрацией списков видов. Геоботанические списки обработаны в компьютерном комплексе «EcoScaleWin» с применением метода средневзвешенной середины интервала по обилию [12, с. 87-89]. Рассчитаны экологические характеристики для всех видов деревьев и кустарников.

При проведении исследований природных ценопопуляций определена реализованная экологическая валентность (REV), рассчитанная по формуле:

$$
R E V=\frac{\sum_{\text {ступеней занимаемых изучением цП по шкале фактора }}}{\text { число ступеней шкалы }}
$$

Для определения использования экологических потенций наиболее распространённых видов древесных растений по каждому фактору приведен коэффициент экологической эффективности (K.ec.eff.), который представляет соотношение REV/PEV, выраженное в процентах [8].

Таблица 1 - Потенциальные, реализованные экологические валентности (PEV, REV), коэффициент экологической эффективности (К. ес. eff.) и индекс толерантности (It) эдификаторов и ассектаторов по шкалам Д.Н. Цыганова, 1983

\begin{tabular}{|c|c|c|c|c|c|c|c|c|c|c|c|c|c|c|}
\hline \multirow[b]{2}{*}{ № } & \multirow[b]{2}{*}{ Вид } & \multicolumn{3}{|c|}{$\mathrm{Hd}$} & \multicolumn{3}{|c|}{$\mathrm{Tr}$} & \multicolumn{3}{|c|}{$\mathrm{Nt}$} & \multicolumn{3}{|c|}{$\mathrm{Rc}$} & \multirow{2}{*}{$\begin{array}{c}\text { It } \\
\text { почв. }\end{array}$} \\
\hline & & PEV & REV & $\begin{array}{c}\text { K.ec. } \\
\text { eff. }(\%)\end{array}$ & PEV & REV & $\begin{array}{l}\text { K. ec. } \\
\text { eff. }(\%)\end{array}$ & PEV & REV & $\begin{array}{l}\text { K. ec. } \\
\text { eff. }(\%)\end{array}$ & PEV & REV & $\begin{array}{l}\text { K. ec. } \\
\text { eff. }(\%)\end{array}$ & \\
\hline 1 & $\begin{array}{l}\text { Betula pen- } \\
\text { dula Roth }\end{array}$ & $\begin{array}{l}0,48 \\
\mathrm{MB}\end{array}$ & 0,17 & 35 & $\begin{array}{l}0,47 \\
\mathrm{MB}\end{array}$ & 0,11 & 23 & $\begin{array}{c}0,82 \\
\text { ЭВ }\end{array}$ & 0,23 & 28 & $\begin{array}{c}0,85 \\
\text { ЭВ }\end{array}$ & 0,38 & 45 & $\begin{array}{l}0,61 \\
\text { ГЭБ }\end{array}$ \\
\hline 2 & $\begin{array}{l}\text { Daphne me- } \\
\text { sereum L. }\end{array}$ & $\begin{array}{l}0,22 \\
\mathrm{CB}\end{array}$ & - & - & $\begin{array}{c}0,33 \\
\mathrm{CB}\end{array}$ & - & - & $\begin{array}{l}0,64 \\
\Gamma Э В\end{array}$ & - & - & $\begin{array}{l}0,54 \\
\text { MB }\end{array}$ & - & - & $\begin{array}{l}0,43 \\
\text { ГСБ }\end{array}$ \\
\hline 3 & $\begin{array}{l}\text { Frangula } \\
\text { alnus Mill } \\
\end{array}$ & $\begin{array}{l}0,48 \\
\mathrm{MB}\end{array}$ & 0,02 & 0,04 & $\begin{array}{l}0,37 \\
\Gamma \mathrm{CB} \\
\end{array}$ & 0,04 & 0,001 & $\begin{array}{l}0,64 \\
\Gamma Э В \\
\end{array}$ & 0,03 & 0,05 & $\begin{array}{l}0,46 \\
\mathrm{MB} \\
\end{array}$ & 0,05 & 11 & $\begin{array}{l}0,49 \\
\text { МБ } \\
\end{array}$ \\
\hline 4 & $\begin{array}{l}\text { Picea obo- } \\
\text { vata Ledeb. }\end{array}$ & $\begin{array}{c}0,30 \\
\mathrm{CB}\end{array}$ & 0,26 & 87 & $\begin{array}{l}0,42 \\
\Gamma \mathrm{CB} \\
\end{array}$ & 0,16 & 38 & $\begin{array}{c}0,82 \\
\text { ЭВ } \\
\end{array}$ & 0,37 & 44 & $\begin{array}{c}0,77 \\
\text { ЭВ }\end{array}$ & 0,31 & 40 & $\begin{array}{l}0,58 \\
\text { ГЭБ }\end{array}$ \\
\hline 5 & $\begin{array}{l}\text { Pinus syl- } \\
\text { vestris L. }\end{array}$ & $\begin{array}{l}0,57 \\
\text { ГЭВ } \\
\end{array}$ & 0,06 & 11 & $\begin{array}{l}0,42 \\
\Gamma \mathrm{CB} \\
\end{array}$ & 0,09 & 21,4 & $\begin{array}{c}0,82 \\
Э \mathrm{~B} \\
\end{array}$ & 0,41 & 50 & $\begin{array}{c}0,86 \\
\text { ЭВ } \\
\end{array}$ & 0,22 & 25,5 & $\begin{array}{c}0,70 \\
\text { ЭБ } \\
\end{array}$ \\
\hline 6 & $\begin{array}{l}\text { Rosa canina } \\
\text { L. }\end{array}$ & $\begin{array}{l}0,65 \\
\text { ГЭВ } \\
\end{array}$ & 0,11 & 17 & $\begin{array}{l}0,37 \\
\text { ГСВ } \\
\end{array}$ & 0,04 & 10,8 & $\begin{array}{c}0,82 \\
Э B \\
\end{array}$ & 0,03 & 3,6 & $\begin{array}{c}1,00 \\
Э B \\
\end{array}$ & 0,05 & 5,0 & $\begin{array}{c}0,68 \\
\text { ЭБ }\end{array}$ \\
\hline 7 & $\begin{array}{l}\text { Sorbus au- } \\
\text { cuparia L. }\end{array}$ & $\begin{array}{l}0,39 \\
\text { ГСВ }\end{array}$ & 0,19 & 49 & $\begin{array}{l}0,47 \\
\text { MB }\end{array}$ & 0,10 & 21,2 & $\begin{array}{c}0,82 \\
\text { ЭВ }\end{array}$ & 0,27 & 33,0 & $\begin{array}{c}0,92 \\
\text { ЭВ }\end{array}$ & 0,24 & 26,0 & $\begin{array}{l}0,65 \\
\text { ГЭБ }\end{array}$ \\
\hline 8 & $\begin{array}{l}\text { Virburnum } \\
\text { opulus L. }\end{array}$ & - & - & - & - & - & - & $\begin{array}{l}0,45 \\
\mathrm{MB}\end{array}$ & - & - & $\begin{array}{l}0,54 \\
\mathrm{MB}\end{array}$ & - & - & $\begin{array}{l}0,49 \\
\text { МБ }\end{array}$ \\
\hline
\end{tabular}

Кроме того, приведён анализ эколого-ценотической структуры растительного покрова, являющийся удобным инструментом изучения фитоценотических смен, так как спектр заключает в себе интегральную информацию о присутствии десятков и сотен видов (рис. 1).

Значения потенциальной экологической валентности, представленные в таблице 1, показывают, что лимитирующими из климатических факторов для Picea obovata являются факторы Тm и Оm. Это объясняется тем, что экологические предпочтения данного вида не вполне соответствуют термоклиматическим и омброклиматическим параметрам Кусинского района. С другой стороны, и обитание в краевых ценопопуляциях приводит к снижению конкурентоспособности.

Особое значение в распространении бореальных видов имеют почвенные факторы. Анализ цифрового материала показал, что ограничивающими для большинства эдификаторов являются факторы увлажнения $(50 \%)$ и трофность $(70,5 \%)$ почв.
Для определения стено- и эвривалентности каждого вида использована экспертная оценка, согласно которой стеновалентными (CB) считаются виды, занимающие $1 / 3$ шкалы; эвривалентными (ЭВ) - более 2/3 шкалы, остальные виды мезовалентные (МВ). Последние были разделены на гемистено- (ГСВ), ме30- и гемиэвривалентные (ГЭВ) фракции.

Распределение видов по группам толерантности традиционное: стенобионтные (СБ), диапазон значений It $<0,34$; гемистенобионтные (ГСБ), он колеблется от 0,34 до 0,45 ; у мезобионтных (МБ) от 0,45 до 0,56 ; у гемиэврибионтных от 0,56 до 0,67 и эврибионтных $>0,67$.

\section{Результаты и их обсуждение}

Для всех видов древесно-кустарниковых синузий, произрастающих в пределах исследуемой территории, количественные показатели приведены в таблицах $1,2$.
Обособленное место занимает шкала Lc, по которой преобладают виды эвривалентной и гемиэвривалентной фракций. Экологическая толерантность эдификаторов и ассектаторов по фактору освещённости обусловливает произрастание их в различных местообитаниях, отличающихся условиями освещенности: от сомкнутого древостоя до экотонов.

Результаты исследования показали, что реализованная экологическая валентность видов древесной синузии значительно ниже потенциальной. Наибольшая степень использования экологических потенций и эффективность освоения экологического пространства отмечена для P. obovata по термоклиматическим $(\mathrm{Tm}, \mathrm{Om})$ и эдафотопическим ( $\mathrm{Hd}, \mathrm{Tr})$ факторам. Это объясняется тем, что данные факторы обладают незначительным диапазоном.

Анализ экологических характеристик местообитаний ценопопуляций видов древесной синузии показал, что по терморежиму и омброрежиму ценоклимата они укладываются в переходные значения, соответственно, от суббореального до неморального $(6,5-8,0)$ и от субаридного до субгумидного; с разни- 
Гетманец И.А., Москвина И.В., Артёменко Б.А.

Анализ экологического пространства эдификаторов и ассектаторов.

03.02.00 - общая биология

цей выпадения и испарения осадков от 0 до топических характеристик: Hd (9-15) соответствуют 400 мм/год $(7,5-9,0)$; по криорежиму - в диапазоне $(5,0-8,0)$ от суровых зим с изотермой самого холодного месяца от $-16^{\circ} \mathrm{C}$ до $-24^{\circ} \mathrm{C}$ до умеренных; по фактору континентальности - в материковом/субматериковом режиме. Ценоклиматический фактор, определяющий световой режим местообитаний, характеризуется широким диапазоном 2,0-6,0, что соответствует режимам открытых/полуоткрытых пространств и светлых/тенистых лесов. Параметры эдафопереходному режиму увлажнения почв от луговостепного до сыро-лесолугового. Показатели трофности (4-7) соответствуют промежуточному режиму от бедных до довольно богатых почв. Показатели кислотности (5-9) свидетельствуют о мезоацидофильном режиме (переходный от кислых до нейтральных почв, с рН 6,5-7,2). Нитрификация почв соответствует диапазону (3-7), что характеризует диапазон от бедных азотомдо достаточно обеспеченных.

таблица 2 - Потенциальные, реализованные экологические валентности (PEV, REV), коэффициент экологической эффективности (К. ес. еff.) и индексы толерантности (It) эдификаторов и ассектаторов видов по шкалам Д.Н. Цыганова, 1983

\begin{tabular}{|c|c|c|c|c|c|c|c|c|c|c|c|c|c|c|c|c|c|}
\hline \multirow[b]{2}{*}{ № } & \multirow[b]{2}{*}{ Вид } & \multicolumn{3}{|c|}{$\mathrm{Tm}$} & \multicolumn{3}{|c|}{$\mathrm{Kn}$} & \multicolumn{3}{|c|}{$\mathrm{Om}$} & \multicolumn{3}{|c|}{$\mathrm{Cr}$} & \multirow[b]{2}{*}{$\begin{array}{c}\text { It } \\
\text { клим. }\end{array}$} & \multicolumn{3}{|c|}{ Lc } \\
\hline & & 跑 & 䒚 & $\begin{array}{l}\mathrm{K} . \\
\text { ec. } \\
\text { eff. } \\
(\%)\end{array}$ & 至 & $\frac{1}{21}$ & $\begin{array}{l}\text { K. } \\
\text { ec. } \\
\text { eff. } \\
(\%)\end{array}$ & 焉 & $\underset{1}{2}$ & $\begin{array}{c}\text { K. ec. } \\
\text { eff. } \\
(\%)\end{array}$ & 焉 & 䒚 & $\begin{array}{l}\mathrm{K} . \\
\text { ec. } \\
\text { eff. } \\
(\%)\end{array}$ & & 嵅 & 䒚 & $\begin{array}{l}\mathrm{K} . \\
\text { ec. } \\
\text { eff. } \\
(\%)\end{array}$ \\
\hline 1 & $\begin{array}{l}\text { Betula pen- } \\
\text { dula Roth }\end{array}$ & $\begin{array}{l}0,53 \\
\mathrm{MB}\end{array}$ & 22,6 & 4 & $\begin{array}{c}0,80 \\
Э \mathrm{~B}\end{array}$ & 0,20 & 25 & $\begin{array}{l}0,40 \\
\Gamma \mathrm{CB}\end{array}$ & 0,10 & 25 & $\begin{array}{l}0,67 \\
\text { ГЭВ }\end{array}$ & 0,18 & 26,8 & $\begin{array}{l}0,60 \\
\text { ГЭБ }\end{array}$ & $\begin{array}{l}0,67 \\
\text { ГЭБ }\end{array}$ & 0,09 & 13,4 \\
\hline 2 & $\begin{array}{l}\text { Daphne me- } \\
\text { sereum } \mathrm{L} .\end{array}$ & $\begin{array}{l}0,53 \\
\mathrm{MB}\end{array}$ & - & - & $\begin{array}{l}0,67 \\
\Gamma Э В\end{array}$ & - & - & $\begin{array}{l}0,40 \\
\Gamma \mathrm{CB}\end{array}$ & - & - & $\begin{array}{l}0,53 \\
\mathrm{MB}\end{array}$ & - & - & $\begin{array}{l}0,53 \\
\text { МБ }\end{array}$ & $\begin{array}{l}0,56 \\
\text { МБ }\end{array}$ & - & - \\
\hline 3 & $\begin{array}{l}\text { Frangula } \\
\text { alnus Mill }\end{array}$ & $\begin{array}{l}0,53 \\
\mathrm{MB}\end{array}$ & 0,03 & 5,6 & $\begin{array}{c}0,70 \\
\text { ЭВ }\end{array}$ & 0,03 & 4,2 & $\begin{array}{l}0,47 \\
\mathrm{MB}\end{array}$ & 0,02 & 4 & $\begin{array}{l}0,47 \\
\mathrm{MB}\end{array}$ & 0,05 & 10,6 & $\begin{array}{l}0,55 \\
\text { МБ }\end{array}$ & $\begin{array}{l}0,78 \\
\text { ЭБ }\end{array}$ & 0,11 & 14 \\
\hline 4 & $\begin{array}{l}\text { Picea obo- } \\
\text { vata Ledeb. }\end{array}$ & $\begin{array}{c}0,29 \\
\mathrm{CB}\end{array}$ & 0,09 & 31 & $\begin{array}{l}0,70 \\
\text { ЭВ }\end{array}$ & 0,17 & 24 & $\begin{array}{c}0,33 \\
\mathrm{CB}\end{array}$ & 0,17 & 51 & $\begin{array}{l}0,53 \\
\mathrm{MB}\end{array}$ & 0,2 & 38 & $\begin{array}{l}0,47 \\
\mathrm{Mb}\end{array}$ & $\begin{array}{c}0,89 \\
\text { ЭБ }\end{array}$ & 0,44 & 49 \\
\hline 5 & $\begin{array}{l}\text { Pinus syl- } \\
\text { vestris L. }\end{array}$ & $\begin{array}{l}0,59 \\
\mathrm{MB}\end{array}$ & 0,12 & 20 & $\begin{array}{c}0,80 \\
Э \mathrm{~B}\end{array}$ & 0,17 & 21 & $\begin{array}{l}0,40 \\
\Gamma \mathrm{CB}\end{array}$ & 0,10 & 0,002 & $\begin{array}{c}0,73 \\
Э \mathrm{~B}\end{array}$ & 0,18 & 24 & $\begin{array}{l}0,63 \\
\text { ГЭБ }\end{array}$ & $\begin{array}{l}0,67 \\
\text { ГЭБ }\end{array}$ & 0,11 & 16,4 \\
\hline 6 & $\begin{array}{l}\text { Rosa canina } \\
\text { L. }\end{array}$ & $\begin{array}{l}0,53 \\
\mathrm{MB}\end{array}$ & 0,03 & 5,6 & $\begin{array}{c}0,80 \\
\text { ЭВ }\end{array}$ & 0,13 & 16 & $\begin{array}{l}0,67 \\
\text { ГЭВ }\end{array}$ & 0,02 & 2,9 & $\begin{array}{l}0,40 \\
\Gamma Э В\end{array}$ & 0,05 & 12,5 & $\begin{array}{l}0,65 \\
\text { ГЭБ }\end{array}$ & $\begin{array}{l}0,67 \\
\text { ГЭБ }\end{array}$ & 0,24 & 35,8 \\
\hline 7 & $\begin{array}{l}\text { Sorbus au- } \\
\text { cuparia L. }\end{array}$ & $\begin{array}{l}0,65 \\
\text { ГЭВ }\end{array}$ & 0,10 & 15 & $\begin{array}{l}0,60 \\
\text { ЭВ }\end{array}$ & 0,11 & 18 & $\begin{array}{l}0,47 \\
\mathrm{MB}\end{array}$ & 0,10 & 0,002 & $\begin{array}{l}0,53 \\
\mathrm{MB}\end{array}$ & 0,09 & 17 & $\begin{array}{l}0,56 \\
\text { МБ }\end{array}$ & $\begin{array}{c}1,00 \\
\text { ЭБ }\end{array}$ & 0,11 & 10 \\
\hline 8 & $\begin{array}{l}\text { Virburnum } \\
\text { opulus L. }\end{array}$ & $\begin{array}{l}0,59 \\
\text { ГЭВ }\end{array}$ & - & & $\begin{array}{l}0,70 \\
\text { MB }\end{array}$ & - & - & $\begin{array}{l}0,40 \\
\Gamma \mathrm{CB}\end{array}$ & - & - & $\begin{array}{l}0,53 \\
\mathrm{MB}\end{array}$ & - & - & $\begin{array}{l}0,56 \\
\text { МБ }\end{array}$ & $\begin{array}{c}0,89 \\
\text { ЭБ }\end{array}$ & - & - \\
\hline
\end{tabular}

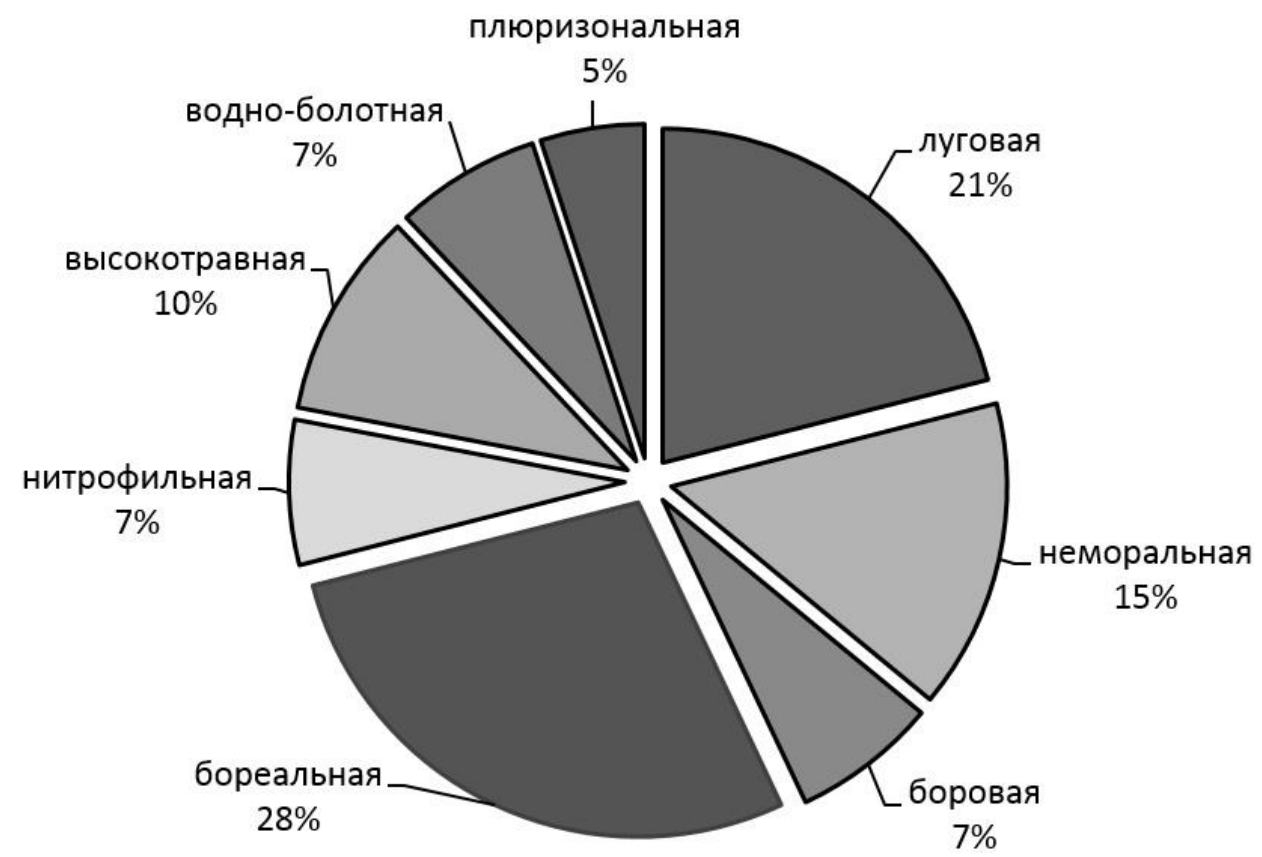

Рисунок 1 - Эколого-ценотические группы западного склоны горы Липовой

Изучение вертикальной структуры и состава древостоя фитоценозов ельника кустарничково-зеленомошного показало, что главная лесообразующая порода $P$. obovata отмечена во всех ярусах, где также присутствуют Betula pendula и Pinus sylvestris, но их численность варьируется в пределах 10-20\% от общего числа всех особей исследуемого участка. Отмечается неравномерность распределения древостоя, хорошо выражены «окна возобновления» с присутствием светолюбивых видов растений. Анализ био- 
Гетманец И.А., Москвина И.В., Артёменко Б.А.

морф показал, что для P. abies характерна жизненная форма - одноствольное дерево с различным характером кроны, что свидетельствует о разном возрасте эдификатора. B. pendula представлена молодыми особями (до 20 лет), тяготеющими к «окнам», в которых наблюдается оптимальный уровень освещения для данного этапа развития. Исследуемый фитоценоз можно отнести к позднесукцессионным сообществам, позднему этапу восстановительной сукцессии, т.к. доминантом является типично конкурентный вид ель сибирская.

Эколого-фитоценотический анализ исследованных сообществ западного склона горы Липовой в пределах территории Кусинского района выявил следующие ЭЦГ по абсолютному числу видов разных ЭЦГ: бореальная, неморальная, лугово-опушечная, нитрофильная, боровая, высокотравная, водно-болотная и плюризональная, их процентное соотношение представлено на рис. 1.

\section{Заключение}

Анализ показал, что в лесном сообществе с доминированием ели сибирской представлен спектр разных эколого-ценотических групп: более трети видов относится к бореальной ЭЦГ (включая боровую), значительный вклад в распределение вносят луговоопушечные (включая высокотравные) и неморальные виды, что свидетельствует о среднем этапе сукцессионных изменений растительного покрова и формировании сомкнутого древостоя с выраженной вертикальной структурой позднесукцессионного вида. Выраженность горизонтальной гетерогенности растительного покрова объясняется мозаикой «окон возобновления». Полученные результаты показывают, что в исследуемом древостое P. obovata имеет онтогенетический спектр, характерный для нормальной популяции в позднесукцесионном древостое.

\section{СПИСОК ЛИТЕРАТУРЫ:}

1. Раменский Л.Г., Цаценкин И.А., Чижиков О.Н. [и др.] Экологическая оценка кормовых угодий по растительному покрову. М.: СельхозГИЗ, 1956. $472 \mathrm{c}$.

2. Ellenberg H., Weber H.E., Dull R. [et all] Zeigerwerte von Pflanzen in Mitteleuropa [Indicator values of plants in Central Europe] // Scripta Geobotanics. Verlag Erich Goltze KG, Gottingen, 1991. Vol. 18. 248 p.

3. Landolt E. Okologische Zeigerwertszur Sweizer Flora // Veroff. Geobot. Inst. ETH. Zurich, 1977. H. 64. P. 1-208.

4. Цыганов Д.Н. Фитоиндикация экологических режимов в подзоне хвойно-широколиственных лесов. М.: Наука, 1983. 196 с.

5. Королюк А.Ю. Использование экологических шкал в геоботанических исследованиях // Всероссийская школа-конференция: Актуальные проблемы геоботаники. Петрозаводск, 2007. С. 176-197.

6. Региональные экологические шкалы для лесной растительности Дальнего Востока / Т.А. Комарова, Е.В. Тимощенкова, Н.Б. Прохоренко [и др.]. Владивосток, 2003. 277 с.

7. Дорогова Ю.А., Жукова Л.А. Экологическая характеристика ценопопуляций липы сердцевидной в подзоне хвойно-широколиственных лесов // Вестник Казанского государственного аграрного университета. 2009. № 2 (12). С. 155-160.
8. Экологические шкалы и методы анализа экологического разнообразия растений: монография / Л.А. Жукова, Ю.А. Дорогова, Н.В. Турмухаметова [и др.]; под общ. ред. проф. Л.А. Жуковой. ЙошкарОла: Изд-во Мар. гос. ун-та, 2010. 368 с.

9. Полянская Т.А. Структура ценопопуляций растений бореальной эколого-ценотической группы лесной зоны Европейской России: автореф. дис. ... дра биол. наук. Казань, 2014. 33 с.

10. Дидух П.Я., Плюта П.Я., Каркуциев Г.Н. Опыт фитоиндикации экологических режимов экотопов долины р. Ворсклы // Ботанический журнал. 1991. Т. 76, № 5. С. 699-709.

11. Заугольнова Л.Б., Быховцев С.С., Баринова О.Г. [и др.] Верификация балловых экологических оценок местообитания с помощью измерения некоторых параметров среды // Лесоведение. 1998. № 5. С. 48-58.

12. Грохлина Т.И., Ханина Л.Г. Автоматизация обработки геоботанических описаний по экологическим шкалам // Принципы и способы сохранения биоразнообразия: сборник материалов II всерос. науч. конф. Йошкар-Ола: Изд-во Мар. гос. ун-та, 2006. C. $87-89$.

13. Широких П.С. Сравнение эффективности оценок экологических условий лесов южноуральского региона при использовании различных экологических шкал // Аграрная Россия. 2009. № 1а. С. 72-73.

14. Зубкова Е.В. О некоторых особенностях диапазонных экологических шкал Д.Н. Цыганова // Известия Самарского научного центра РАН. 2011. T. 13, № 5. C. 48-53.

15. Золотова Е.С., Иванова Н.С. Использование шкал Д.Н. Цыганова для анализа экологического пространства типов леса Среднего Урала // Фундаментальные исследования. 2015. № 2 (23). С. 51145119.

16. Серебренникова Ю.А., Гетманец И.А Экологическое разнообразие видов древесной синузии в подзоне южно-таёжных лесов Челябинской области // Вестник Оренбургского государственного педагогического университета. 2017. № 2. С. 29-37.

17. Ниценко А.А. Об изучении экологической структуры растительного покрова // Ботанический журнал. 1969. Т. 54, № 7. С. 1002-1014.

18. Рогова Т.В., Прохоров В.Е., Шайхутдинова Г.А. [и др.]. Электронные базы фитоиндикационных данных в системах оценки состояния природных экосистем и ведения кадастров биоразнообразия // Учёные записки Казанского университета. Сер. Естественные науки. 2010. Т. 152. Кн. 1. С. 174-181.

19. Соколова Л.А. Основные черты растительности западного склона (северной части Южного Урала) // Труды Ботанического института АН СССР. 1951. Сер. 3. Вып. 7. С. 134-180.

20. Симонов А.В. Куса. Челябинск: Юж.-Урал. кн. изд., 1977. 63 с.

Статья публикуется при поддержке гранта ФГБОУ ВО «Мордовский государственный педагогический институт им. М.Е. Евсевьева" по договору на выполнение научно-исследовательских работ от 14.04.2017 2. № 16-449 по теме "Биоиндикационная оценка природных зон Южнного Урала с использованием энтомофауны». 


\title{
ECOLOGICAL CHARACTERISTICS OF EDIFICATORS AND ASSECTATORS OF THE SOUTHERN TAIGA FORESTS OF THE CHELYABINSK REGION
}

(C) 2017

Getmanets Irina Anatolievna, doctor of biological sciences, head of General Ecology Department

Moskvina Irina Valerievna, postgraduate student of General Ecology Department

Chelyabinsk State University (Chelyabinsk, Russian Federation)

Artemenko Boris Alexandrovich, candidate of biological sciences, acting head of Theory, Methods and Management of Preschool Education Department

South Ural State Humanitarian Pedagogical University (Chelyabinsk, Russian Federation)

\begin{abstract}
The following paper deals with the phytoindication of ecotopes of spruce forests on the western slope of Mount Lipovaya within the territory of the Kusinsky District. This phytoindication was made on the basis of D.N. Tsyganov's ecological scales and with the help of «EcoScaleWin» computer software. The cenotic properties of species are estimated by their abundance in typical communities; limiting factors, ecological valence and tolerance are determined; the degree of use of ecological potencies and the efficiency of development of ecological space are estimated and the aggregate parameters of habitats are described. The vertical structure and composition of spruce stands are estimated, it is shown that Picea obovata is noted in all tiers, where Betula pendula and Pinus sylvestris are also present, but their numbers range from $10-20 \%$ of the total number of individuals in the study area. The unevenness of the distribution of the stand is noted. The ratio of the species of eco-and-coenotic groups is analyzed and it is shown that in the communities the species of the boreal and boron groups are predominated, the nemoral and meadow (including tall grass) groups contribute significantly, a small percentage belongs to the non-forest group species (wetland and plurizonal).

Biomorphological analysis revealed that the life form is stable, it is represented by a single-stem tree with different shape of the crown, which indicates the different ages of Siberian spruce. The investigated phytocenosis is attributed to the late succession communities, the late stage of restorative succession, because the dominant is a typically competitive species. The research materials can serve as a basis for plant communities and coenotic populations monitoring, for identifying of the potential species richness of phytocenoses.

Keywords: tolerance; ecological valence; ecological scales; phytoindication; edificators; assectators; ecologycenotic groups; ecotope; coenotic population; phytocenosis; spruce stand; Chelyabinsk Region; Kusinsky District; geobotanical descriptions; Mount Lipovaya.
\end{abstract}

\section{РАЗНООБРАЗИЕ КУЛЬТИВИРУЕМЫХ ГЕТЕРОТРОФНЫХ БАКТЕРИЙ, ВЫДЕЛЕННЫХ ИЗ ПОВЕРХНОСТНЫХ ВОД БУХТЫ ВОСТОК ЯПОНСКОГО МОРЯ}

(C) 2017

Голозубова Юлия Сергеевна, аспирант кафедры экологии

Бузолева Любовь Степановна, доктор биологических наук, профессор, профессор кафедры биоразнообразия и морских биоресурсов

Богатыренко Елена Александровна, кандидат биологических наук, доцент кафедры биоразнообразия и морских биоресурсов

Ким Александра Вячеславовна, аспирант кафедры экологии

Еськова Алена Игоревна, аспирант кафедры биоразнообразия и морских биоресурсов Дальневосточный федеральный университет (2. Владивосток, Российская Федераиия)

Аннотация. В данной статье рассматривается таксономический состав культивируемых гетеротрофных микроорганизмов поверхностных вод бухты Восток залива Петра Великого Японского моря. В бухте Восток общая численность гетеротрофных микроорганизмов составила 2,03-10 $0^{5} \mathrm{OE} /$ мл, что позволяет отнести эти морские воды к мезосапробным. Микроорганизмы, выделенные из данной прибрежной акватории, представлены 4 филумами. Среди культивируемых микроорганизмов доминировали представители филума Proteobacteria, на долю которых пришлось более 50\% от всего таксономического разнообразия культивируемых бактерий бухты Восток. Также были выделены бактерии филумов Bacteroidetes, Firmicutes и Actinobacteria. Taксономическое разнообразие сообщества бухты Восток было представлено 14 родами. На основании фенотипических признаков культивируемые гетеротрофные бактерии отнесены к Rhodococcus sp., Micrococcus sp., Actynomycetes sp., Bacillus sp., Sarcina sp., Pseudomonas sp., Acinetobacter sp., Arthrobacter sp., Vibrio sp., Halomonas sp., Flavobacterium sp., Acetobacter sp., Marinococcus sp., Pseudoalteromonas sp., Aeromonas sp., и Staphylococcus sp. Санитарно-показательные бактерии в данной бухте не были выявлены, что свидетельствует о незначительном антропогенном влиянии. Таким образом, бухта Восток действительно испытывает незначительный рекреационный стресс отдыхающих, что отражается на составе морского микробного сообществ.

Ключевые слова: культивируемые гетеротрофные микроорганизмы; таксономический состав; сообщество; антропогенное загрязнение; морские микроорганизмы; экологический мониторинг; Японское море; залив Петра Великого; залив Восток; санитарно-показательные микроорганизмы. 